\title{
Interior Environment Enhancing Child Development
}

\author{
Nipattha Noiprawa, Nopadon Sahachaisaeree \\ Faculty of Architecture, \\ King Mongkut's Institute of Technology Ladkrabang, Thailand \\ nongmang28@hotmail.com
}

\begin{abstract}
Environment has been a crucial factor determining the effectiveness of medical treatment, especially for mentally related disorders. The study uses the autistic treatment environment as a case study to examine relevant environmental factors supporting the learning process of autistic children towards an environmental design model, the improvement in behavior, and be able to stabilize the patient's emotion. Results from the study are useful for the prognostic study in autism. The final modeling could be applied as a part of special educational programs to extenuate the behavioral and emotional disorders, and to improve the social skills in autistic children.
\end{abstract}

Keywords: Physical Treatment, Interior Environment, Child Autistic

eISSN 2514-751X @ 2017 The Authors. Published for AMER ABRA by e-International Publishing House, Ltd., UK. This is an open-access article under the CC BY-NC-ND license (http://creativecommons.org/licenses/by-ncnd/4.0/). Peer-review under responsibility of AMER (Association of Malaysian Environment-Behaviour Researchers), ABRA (Association of Behavioural Researchers on Asians) and cE-Bs (Centre for EnvironmentBehaviour Studies), Faculty of Architecture, Planning \& Surveying, Universiti Teknologi MARA, Malaysia.

https://doi.org/10.21834/aje-bs.v2i5.222 


\subsection{Introduction}

Autism is a disorder of social development, language and communication. Autistic children have inappropriate behaviors and attention. Autism varies in symptoms. One of the many characteristics is that autistic children isolate themselves and show less attention to their environment. They hardly speak or have difficulties in communication. Some do not respond or have less eye contact when they are called. They neither care for other children nor have proper play. Autistic children are obsessed with certain things and have difficulties in imagination. They sometimes have an attention deficit hyperactive disorder. Since they are development impaired in personal interaction development, they do not accept stimulus from outsiders. In other words, they respond to stimulus for a short period and are often easily distracted by the surrounding stimuli (Academic Supervisory Division, Department of General Education, and Ministry of Education 2001).

It is believed that having a firm concentration on one's thought and action will result in one's wisdom and intellect. Due to the functional impairment of the central part of their brain as well as other neural transmitter malfunction, autistic children hardly concentrate on their activities. This leads to their lack of opportunities to participate in social interactions. Consequently, an attempt to develop their concentration is very important and necessary. Behavior conditioning and learning enhancement can maintain appropriate behaviors; limit improper actions; and formulate desirable behaviors. Teaching them in real situations will best reinforce their social skills.

Learning environment is important in promoting the development of autistic children. Various design environments can attract and stimulate their interest when they participate skill enhancing activities. Therefore, to create an appropriate environment to enhance and develop their behaviors, emotional and social aspect will accommodate autistic children to live as normal children.

There are various activities to enrich the autistic children's development. The most popular method which is allocated in a curriculum of many special education schools is activity therapy. Activity therapy is an activity which helps develop emotion, intellect, concentration, creative thinking as well as the muscle fibers and motor skills. Besides, this therapy helps stimulate communication and enhance social skills.

According to afore mentioned rationale, the reinforcement of special education for children with special needs is very necessary, especially for autistic children who have concentration deficit in their learning process. In the same way, providing an appropriate environment for their learning is also needed to be launched gradually. As a result, the study of physical environmental factors in a focused area in which special education is provided to promote autistic children's developments is conducted. Under the appropriate circumstances and activities that enhance their development, this research will later lead to the appropriate modeling of environment for autistic children.

Thus, the purpose of this paper is to study essential factors which affect in designing proper environments, activities and the modeling of environment enhancing for autistic 54 
children's development. The research question is; what are the interior physical factors of environment which enhance autistic children's development? The objectives of this research are to 1) study the specific characteristics of autistic children, 2) explore skill enhancing activities, 3) study the physical environment affecting the efficiency of skill enhancing activities and 4) to formulate the model of environment which promotes autistic children's development. Hypothesis: The study proposed a hypothesis that enhancing activities for autistic children under the appropriate circumstances result in their proper development.

\subsection{Literature Review}

\section{Characteristic of autism}

Autism is a disorder of neural development and impairment, which include social interaction, communication, emotion, repetitive behaviors, imagination, and sensory abnormalities as well as other symptoms. For social interaction impairment, autistic children have difficulties in interacting with people and their environments. They have less eye contact, facial expression; then, they have less interaction with other people. Second, communication impairment includes language usage, comprehension, meaning and communication. Behavioral and emotional impairments are repetitive abnormalities such as moving/playing their hands or turning around, some children stick on to something; obsess with certain objects; and have limited interest. Some cannot adjust themselves to changes in daily life. Some autistic children express undesirable behaviors which are not appropriate to their age. For the impairment of repetitive behavior, imagination and sensory skills, they have difficulties in controlling and coordinating their motor skills such as muscular mechanism. For other symptoms, some children have restless behaviors while some are slow and inactive.

Learning limitation and conditions include language and communication, social interaction and emotion, behavior and repetition, sensory perception, imaginative thinking, learning ability and physical development. Influential factors during pregnancy and child delivery as well as biological factors such as chemical unbalance of the brain, neural system can cause the malfunction of the brain which results in autism.

Autistic Symptom Levels Mild autism or high-functioning autism refers to the children who are normal or more intellectual. These children have better language development but still encounter social interaction impairment and perception of other people's emotion or feeling. Moderate autism indicates the slow development of language and communication, social interaction, learning ability as well as self-reliance and self-stimulating behaviors. Severe autism is shown in slow developments of all aspects and can occur with retarded and violent behavior.

In this research, autistic children characteristics are divided into different groups 
according to their symptom levels. Moreover, the researcher can identify particular behaviors which are shown and driven by internal factors during the study. The limited area of research can help categorized conditions of autistic children based on the hypothesis.

\section{Child development concept}

Activity therapy is a healing art which promotes, prevents, cures and rehabilitates physical and mental health regarding to the foundation of medical sciences and fundamental theories of psychology.

Development activities are designed to promote the improvement of emotion, intellect, concentration, creative thinking as well as muscle fiber development and physical movement coordination. Furthermore, the activities also enhance and stimulate communication and social skills, repair, maintain and develop mental and physical health.

In this section, the literature review is conducted to study activities used as a tool to collect the data by observing children's behaviors under the study circumstances.

\section{Concept of environment}

The ultimate purpose in accommodating the environment for autistic children is to enable them to learn and be self-motivated to do things. Structured Teaching is applied to enable students to understand and complete the tasks by themselves (Kiratinon Chanpraphai, CIA Autism Resource Center (Singapore)) under the appropriate environment in their classroom (Physical Structure).

The best social enhancement is to teach children in the real circumstance. Children have fewer opportunities to experience varieties of situation in their house while they have more chances to meet people, learn the individual characteristics outside their houses. They learn what others do, play, and even invite other children to join and learn from their activities. Children will perceive and pay more attention to the environment as well as imitate in order to have better opportunities for development.

In this section, it shows that good environment could enhance and promote autistic children's learning development. Appropriate circumstances can affect autistic children's development in many aspects according to those enhancing activities. Especially, peer group learning can contribute to an imitation, which is a part of proper development. The study of environment plays an important role in selecting the study aresa in a classroom.

\subsection{Methodology}

This research focuses on autistic children who are three years of age or older. Autism can be obviously seen when children are three years old. (Sriruan Kaewkangwan, 1982: 208) The research can be categorized into three levels: mild autism, moderate autism and severe autism. Autism of each level leads to various behaviors and different levels of sensory perception impairment. The study conducted for each level by observing autistic children 56 
and the environments in the activity room at the Research and Development Center of Autistic Inclusive Education of Demonstration School, Khonkaen University. Based on activities that enhance the children's skills, the data was collected from

1. Questionnaires about general information of autistic children completed by their mentors.

2. Video records and notes of autistic children's behaviors in details.

3. Survey and records of physical environments in the study area. As seem in Figure 1:

\section{Physicalenvironments}
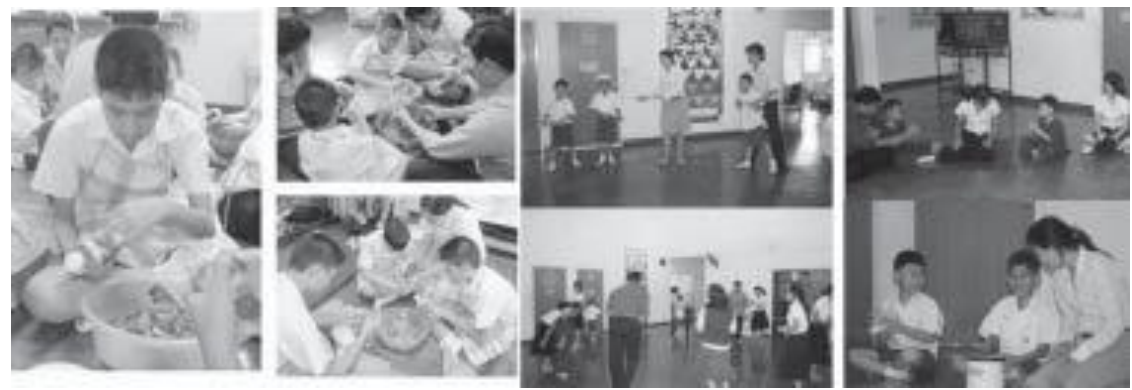

Figure 1: Physical environments

These research tools were used to compare the differences of activities in the selected environment. During the recording on their behaviors, the researchers concentrated on the period of their attention, patterns and frequency of behaviors, the way they look at objects, touch, and make sounds as well as their interaction throughout the activities. As seem in Figure 2: Conceptual Framework and Figure 3: Conceptual Framework and Connection of Variables.

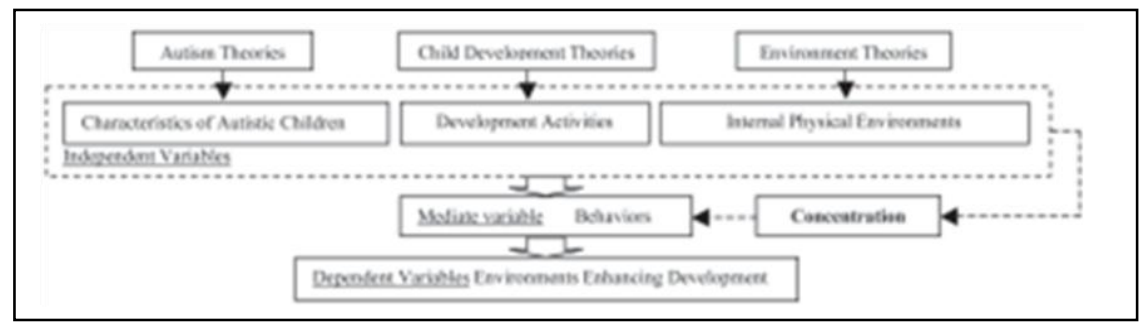

Figure 2: Conceptual framework 


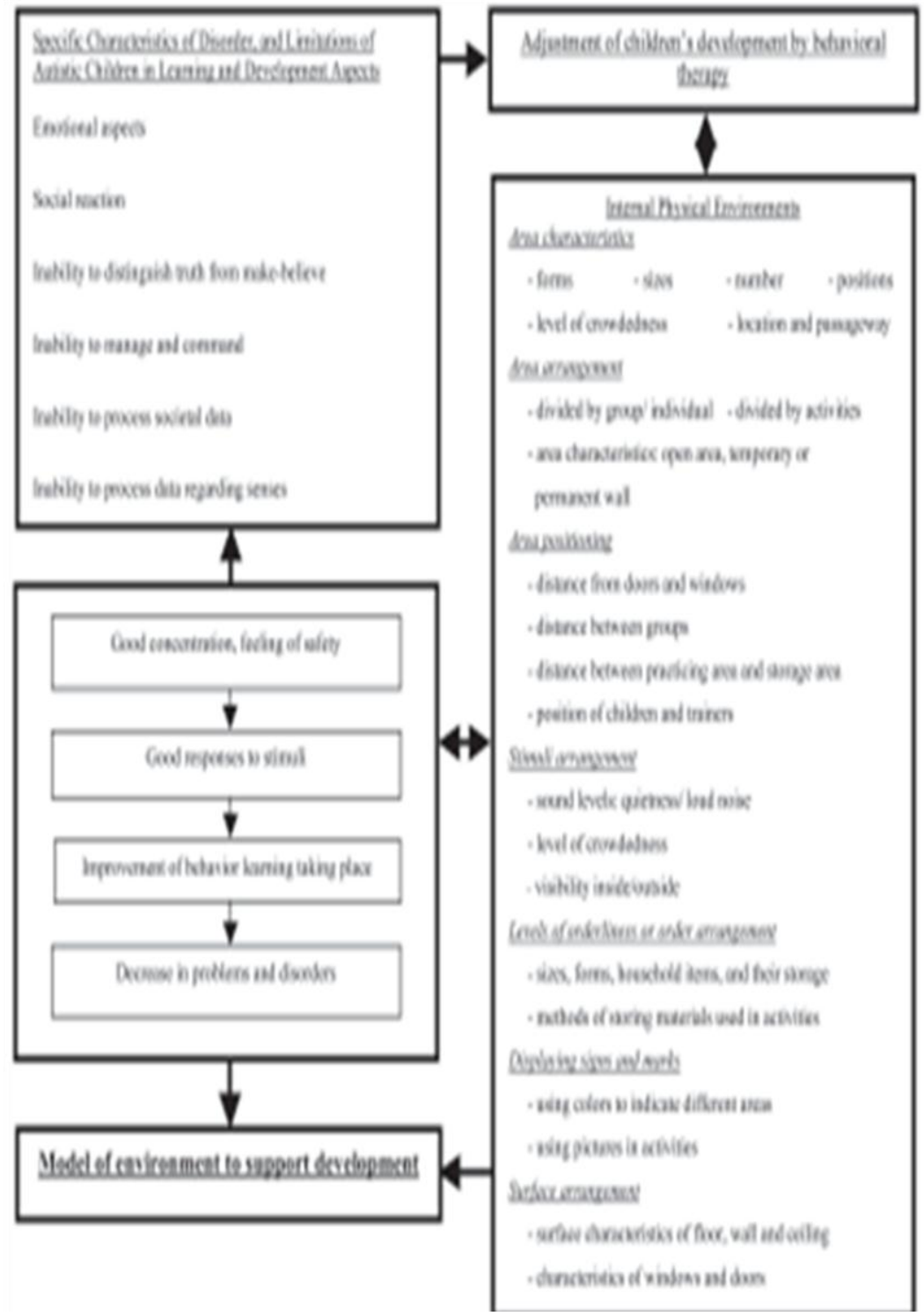

Figure 3: Conceptual framework and connection of variables 
Table 1: Operationlization

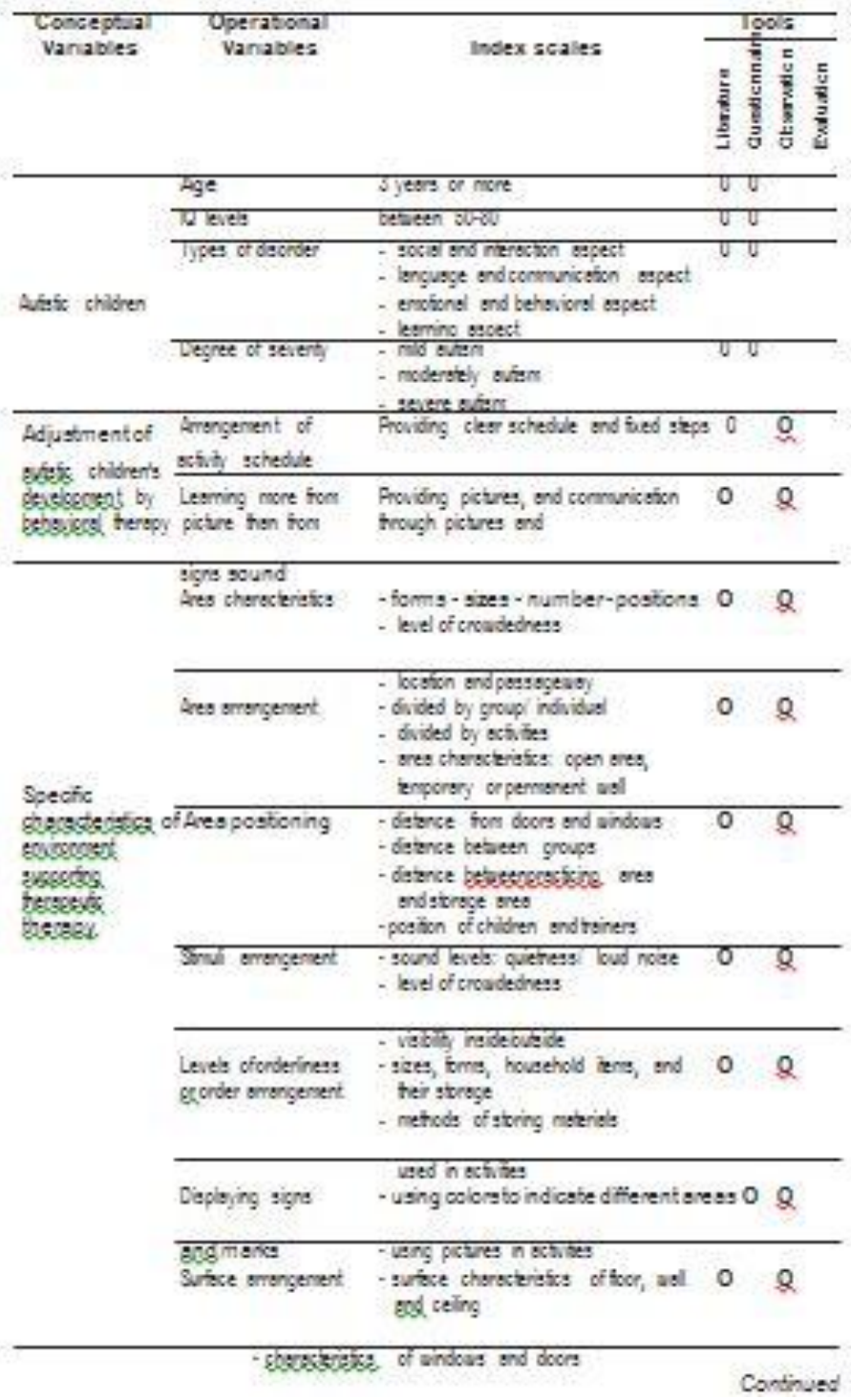




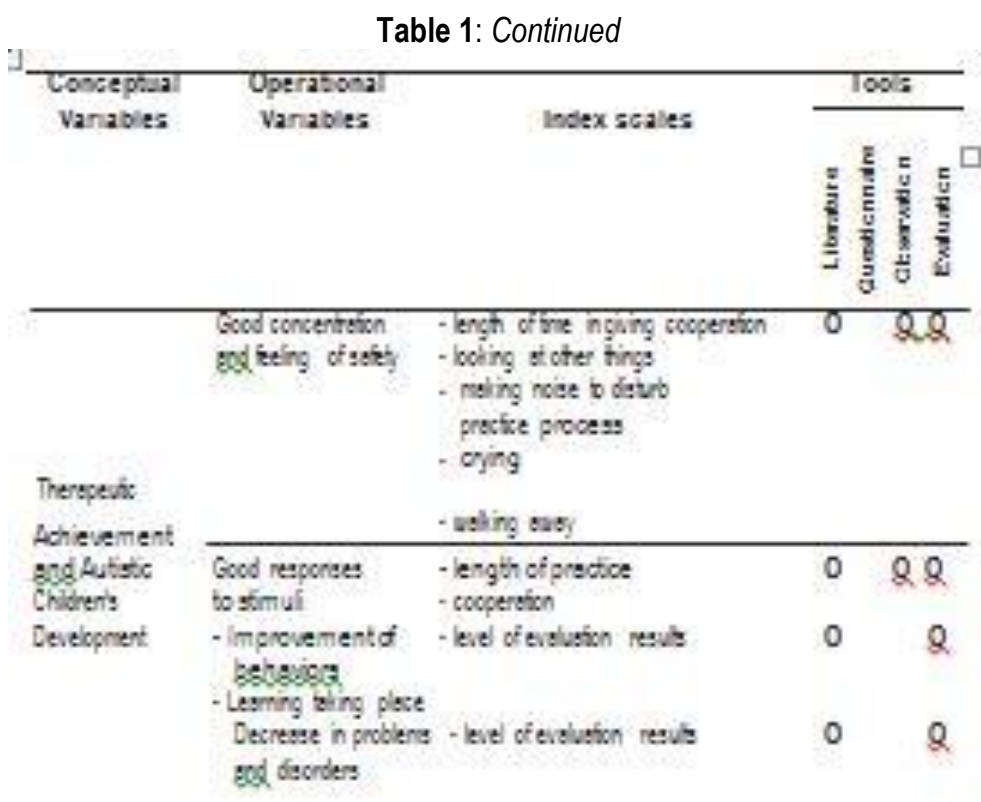

\subsection{Results and Discussions}

The results of this study are guidelines to create a physical environment in a classroom that enhances appropriate development of the autistic children and their concentration during activities. Designing the environment for autistic children, we have to prepare clean, wellventilated and enough spaces for their activities. Moreover, the room should be divided into sections for group and individual activities. Reading corner or other activities should be initiated. Convenient equipments or facilities should be provided. The room must not been disrupted by noises from the outside. More importantly, the area should not be open or accessed to passer-bys or outsiders when they are doing activities in order to minimize the stimuli.

\subsection{Conclusions}

Privacy and territoriality are crucial factors governing the effectiveness of the environment as well. While some environmental stimuli are necessary to draw the patients' attention from the rigor of therapy, unwanted and exaggerated stimulus should be reduced to balance the patients' concentration. A moderately designed interior environment as mentioned earlier can foster a more effective result of Physical Treatment for Child Autistic situation. 
A sound enabling environment for decent treatment should, provide sufficient privacy and the sense of territoriality, while environmental stimulus should be controlled and minimized. A single focal point within the interior environment should be sufficient to draw the attention of patients would be appropriate to enhance the compliance of Child Autistic with the activities, by which the level of effectiveness could be increase.

\section{Acknowledgement}

This research cannot be accomplished without the assistance and inspiration of Assoc. Prof. Dr. Nopadon Sahachaisaeree towards research issue and methodology. I would like to express my sincere gratitude to the autistic child development officers who tirelessly work behind the development of the unfortunates. And I would like to thank also express my gratitude for the autistic children's families who contribute invaluable information to the research.

\section{References}

Berger, D.S. (2002). Music Therapy. Sensory Integration and Autistic Child. London: Jessica Kingsley Publishers.

Fisher, A.G., Murray E.A. \& Bundy, A.C. (1991). Sensory Integration. Theory and Practice.

Philadelphia: F.A. David Company.

Kathy Savage-Hubbard \& Rose, C. Specher. (1993). Paint Adventures. Hong Kong: F\&W Publication, Inc.

Kris, E. (1952). Psychoanalytic exploration in art. New York: International Universities Press.

Niec, L.N. \& Russ, S.W. (2002). Children's internal representations, empathy, and fantasy play. A validity study of the SCORS-Q. Michigan: Psychological Assessment.

Research and Development Center of Autistic Inclusive Education of Demonstration School Khonkaen University. (2009), 7 April 2010. http://home.kku.ac.th/autistic/th/ index.php 